SEP 161963

\title{
SC-R701
}

MASTER

Sandia Corporation

R E P R I N T

$$
\text { CONF-147-3 }
$$

\section{THE STANDARDS LABORATORY PHYSICAL STRUCTURE}

\author{
by \\ J C O'Neal
}

Facsimile Price $\$$

Microfilm Price \$

Available from the

Office of Technical Services

Department of Commerce

Washington 25, D. C. 


\section{DISCLAIMER}

This report was prepared as an account of work sponsored by an agency of the United States Government. Neither the United States Government nor any agency Thereof, nor any of their employees, makes any warranty, express or implied, or assumes any legal liability or responsibility for the accuracy, completeness, or usefulness of any information, apparatus, product, or process disclosed, or represents that its use would not infringe privately owned rights. Reference herein to any specific commercial product, process, or service by trade name, trademark, manufacturer, or otherwise does not necessarily constitute or imply its endorsement, recommendation, or favoring by the United States Government or any agency thereof. The views and opinions of authors expressed herein do not necessarily state or reflect those of the United States Government or any agency thereof. 


\section{DISCLAIMER}

Portions of this document may be illegible in electronic image products. Images are produced from the best available original document. 


\section{Presented at: Instrument Society of America, Pittsburgh, Pennsylvania. September 1963.}

Published by Sandia Corporation, a prime contractor to the United States Atomic Energy Commission

\section{LEGAL NOTICE}

This report was prepared as an account of Government sponsored work. Neither the United States, nor the Commission, nor any person acting on behalf of the Commission:

A. Makes any warranty or representation, expressed or implied, with respect to the accuracy, completeness, or usefulness of the information contained spect to the accuracy, completeness, or usefulness of the information contained disclosed in this report may not infringe privately owned rights; or

B. Assumes any liabilities with respect to the use of, or for damages resulting from the use of any information, apparatus, method, or process disclosed in this report.

As used in the above, "person acting on behalf of the Commisșion" includes any employee or contractor of the Commission, or employee of such contractor, to the extent that such employee or contractor of the Commission or employee of such contractor prepares, disseminates, or provides access to, any information pursuant to his employment or contract with the Commission, or his employment with such contractor. 
J. C. O'Neal

September 1963 


\author{
J. C. O'Neal \\ Mechanical Engineer \\ Primary Standards Laboratory \\ Sandia Corporation \\ Albuquerque, New Mexico
}

\section{ABSTRACT}

The standards laboratory requires a unique physical structure to assure adequate calibration environments. To obtain optimum facilities, operators and planners of standards laboratories must consider building location and construction, room sizes and room arrangement, entrances and windows, utilities, and internal environment control. Existing structures may be modified to meet some calibration requirements.

\section{INTRODUCTION}

Several papers have been written about particular standards laboratories environments. In this paper I will try to cover the main aspects of plaming the total laboratory strusture--the general building shell and the material and devices within the shell required to provide proper environments for a standards calibration program. These environments must be adequate not only for storage, preparation for calibration, and calibration of test items, but also for receiving, unpacking and precleaning, and repacking and preparation for shipment. The laboratory structure considered here includes areas for calibration or measurement of the following: dimension, mass, electrical characteristics, and environments.

First, let us outline and discuss information to be sent to plant engineers, architects, and consultants. Then we will go into various aspects of laboratory planning and some methods of combating unfavorable environments within existing laboratory structures.

This paper is based on the approach that standards laboratories will become more like low-classification cleanrooms in their quest for greater accuracies and precision. I hope that the paper will highlight the need for standardizing requirements for the total laboratory structure in the way cleanroom requirements are being standardized.

\section{PLANNING INFORMA TION AND CRITERIA}

Company policies may require that the design of the standards laboratory conform with general plant architectural schemes. However, the standards laboratory operator or planner should prepare his own sketches and information for plant engineers and consultants. Six areas should be covered:

1. Location of Laboratory -- vibrations, bed rock, particulate fall out, and corrosive vapors.

2. Room Arrangements and Dimensions.

3. Structural Shell.

a. Outside walls -- material (masonry, frame, metal, or glass), color, and finish.

b. Inside walls -- material, color, finish, joint sealing, and ledges.

c. Ceilings -- material (perforations), air distribution, color, and finish.

d. Floors -- slabs (loads and isolation), coverings, material, color, finish, and joint sealing.

4. Entrances and Windows.

a. Entrance doors -- size, material, color, finish, location, and special hardware.

b. Airlocks -- size, material, color, finish, location, foot cleaners, and warning horns.

c. Windows (none in outside walls but windows in lab walls for visitor control) -- size and location.

d. Pass boxes -- number, size, and location (traffic cleanliness control). 


\section{Utilities.}

a. Lighting -- foot-candles, switching, reflection, glare, shielding, and servicing.

b. Electric power -- regulation and number, rating, location of outlets.

c. Gases, water, air, and vacuum -- locations, outlet size, and pressures.

d. Vacuum cleaning system (installed or portable) -- location of tank and outlets.

e. Intercommunication system telephones -controls, number of units, and locations.

6. Environment.

a. Temperature variations and rate of change.

b. Relative humidity variations.

c. Vibration shock limitations.

d. Dust and corrosive vapors control -particle counts or classification.

e. Electrical and radio frequency noise.

f. Acoustic noise.

Information on all these points should be complete as possible, stated in readily understood language. The danger is not putting down enough information rather than too much. If the plant engineer prepares these requirements, we must be certain that we understand what he is specifying. He also must understand the importance of these requirements when dealing with the architect and the contractors. More than one isolated slab--in the specification stage--has ended up as a solid slab attached to the walls because of lack of adequate communication and understanding.

It is wise to have some one from the standards laboratory staff follow the construction through; this is the one way to get what we want. This person must be taught the importance of the requirements beforehand and he must be vested with enough authority to halt construction when these requirements are not being met. We cannot expect men in other organizations to have the same interest in the laboratory requirements that we do, or to fight for compliance with the same degree of vigor that we would. One other major point--we should always indicate how and where the environments such as temper ature, humidity, vibration, lighting, dust, electrical and RF noise, and audio noises will be measured.

\section{Location of Laboratory}

First, we should make a vibration and shock survey at the proposed site of a new standards laboratory. Geological or seismographic disturbances often exist at. amplitudes and freyuencles that will determine whether or not to huild a laboratory at a given location. If we must build at unusually disturbed locations, the architcctural engineer may need to call in a vibration consultant.

Before attaching a laboratory to a bed rock site, we uught to survey not only the vibration conditions and the geometry of the bed rock, but also the nature of industrial concerns in operation and anticipated to be in operation during the next 20 years. Admittedly it is impossible to foresee all of the building changes that can occur or forecast all of the types of industrial concerns that can move in during a 20-year period. But if the laboratory is to be placed in or near an extensive horizontal layer of bed rock, nearby operations involving rolling mills, punch pressee, compressors, diesel engines, and similar vibration sources may wreak havoc with some measurement activities.

We should also try to avoid areas of high particulate fallout when choosing a location, i.e., close proximity to power house smoke stacks, industrial smoke stacks, cement plants, sand or gravel grading operations, fertilizer plants, grain storage areas, and similar particulate matter sources. The closer a standard laboratory resembles (or functions with) a cleanroom operation, the more important remoteness from such fallout-producing operations becomes. And before determining a fallout solution, the direction of prevailing winds should be checked.

\section{Room Arrangements and Dimensions.}

Proper room arrangement can minimize many problems in the standards laboratory. To reduce the traffic, for example, calibrating activities handling high work volumes should be located close to the receiving-disbursing area. Also, it may be advisable to locate activities servicing heavy equipment near the receiving area. 
Vibration problems should be anticipated at every step in room layout. Possible effects of elevator vibrations in the calibration areas should be considered; sensitive instruments, such as reflecting galvanometers and optical read out equipment, should be kept away from such sources of vibration. Good vibration isolation may eliminate the need of extra precautions but we have no need to risk trouble by poor equipment placements. Generally, singlestory buildings are subject to less vibration difficulties than multistory buildings.

Several kinds of operations need to be separated or isolated. Any storage areas next to receiving areas should be surrounded by walls and closed doors to keep particles from the unpacking and cleaning operations out of the storage space. Receiving areas ought not to be on the north side of buildings because material . handling can be difficult during icing conditions in the winter. High- and low-level radiation standards operations should be separated to prevent cross-talk scattering. All possible interferences between operations should be considered in the layout stage.

For efficiency's sake, desks and report writing equipment sometimes are placed in the actual measuring area. This may be a misuse of expensive and hard-to-justify space. The nearer a laboratory approaches current cleanroom costs of up to $\$ 70$ per square foot--with office space at only $\$ 20$ per square foot--the more critical the need for separate office space becomes. Air conditioning costs alone approach $\$ 20$ per square foot in temperature zones of $68 \pm 1 / 4^{\circ} \mathrm{F}$, or closer tolerances with humidity control.

But not only can construction costs be reduced by separating the office and measuring activity; heat loads and noise levels will be reduced as the number of people in the room is reduced. Where supervisory observations and surveillance of the operation is necessary, the supervisor's office or desk space can be placed adjacent to the work activity. His observations can be made through thermopane-type windows without seriously affecting the heat load or temperature control.

Room shapes are generally rectangular to conform to furniture shapes. Actual dimensions are controlled by the amount of equipment, arrangement of operations, and number of people in the rooms. Material and personnel movements through long narrow rooms, for example, can be very distracting and can stir up more dirt.

There are still other considerations which might affect decisions on the size of rooms. For one thing, a square shape affords more floor space per length of wall perimeter than rectangular shapes. Also, the smaller the space and the smaller the perimeter, the easier the temperature control. And tightly-controlled temperature requirements, such as $\pm 1 / 10$ or $1 / 20^{\circ} \mathrm{F}$, can be maintained more easily in areas surrounded by air controlled within $\pm 1 / 4^{\circ} \mathrm{F}$ (a room within a room) than when one or more walls are outside walls subject to greater temperature extremes.

Ceiling heights should allow for an overhead plenum chamber. The height of the plenum chamber will need to be worked out with the air conditioning engineer. Because of direct exposure to the sun, single-story buildings will require special heat radiation shielding above the plenum chamber over and beyond the normal heat loss insulation.

\section{St.ructura] Shell.}

Outside walls -- Masonry walls are generally preferable to metal walls because masonry is more stable and has better vibration absorption. Masonry resists dust infiltration well, but metals walls can be sealed effectively against dust infiltration by using foamed-in-place insulation. Greater care will be required in protecting against noise levels in metal buildings with nonrigid side panels. If we use walls of high reflectivity glass, such as are used in Bell Laboratories' new building at Holmdel, New Jersey, the building should be designed with perimeter halls. Also, calibration areas should be kept away from such outside walls.

Inside walls -- A smooth, hard, finish is desirable. Such a finish can be put on most common wall materials but is easier to obtain on stainless steel, aluminum, or galvanized steel. The more economical materials such as galvanized steel, steel, gypsum board (dry wall), or plaster should be covered with a nonflaking or nonshedding paint. All joints should be well sealed, and corners and ledges should be kept to a minimum. Metal foils provide good humidity barriers at joints and behind pervious materials. 
Plastic materials offer tough, durable, cleanable finishes. When sealed at all joints this material is a good humidity barrier. Thin films of such plastics are bonded to aluminum, steel, other metals, plywood, cement-asbestos, wood, and reinforced plastics. Architectural engineers will have literature on sources of such materials.

Beige walls have been recommended for confined areas by several psychological studies ${ }^{1}$ and many measurement areas could be considered confined areas. A receding color such as light green would be the second choice. Brighter colors such as light yellow (not within the field of vision) are good for gaining the benefit of reflectivity.

Temperature can be best regulated by passing the return air through the floor or points near the floor and then around the room through hollow walls. The more nearly complete and uniform the flow of air in the hollow walls, the better the temperature regulation. Perforated metal studs allow horizontal as well as vertical flow of air; this type of construction is compatible with grated floors for return air flows.

Ceilings should be of perforated, nondust producing material with air distribution capability. (Many mineral fibre materials are dust producing.) The ceiling tile and ceiling support should be rigid enough to prevent undue differential movements between the ceiling and light fixtures.

Air distribution through perforated ceiling tile provides uniform flow at low input velocities Uniform air flow is more compatible with closely-toleranced temperature and humidity characteristics than other methods of air distribution. Uniform flow also reduces the number of control sensors required.

Floors - - Floor slabs in the measurement areas should be isolated from the building and ground. Local geological disturbances may be so minor at the time of building that isolation from earth or bed rock movements seem unnecessary. Yet isolated slabs could become important as the plant or other plants in the vicinity add machinery and manufacturing operations.
Suspension of floor slabs on springs offers one of the most dependable methods of isolation available. ${ }^{2}$ Sand, gravel, cork, and foam isolation beds tend to pack with time and their transmissibility coefficients and natural frequencies change. Cork and foam-type isolation materials have undesirable resonance points which may not sufficiently isolate the slab at the necessary frequency level. A survey should help determine a solution to this problem. Since alkaline moisture harms cork, all cork used for isolation must be sealed against moisture. Floor slabs, of course, should be free of all mechanical piping since such piping can transmit vibrations to measuring equipment. Also, electrical conduits must be provided with nonrigid connectors at the walls or slab boundaries.

Floors are an often-overlooked source of dirt or particulate matter in the standards laboratory. Shear forces from foot traffic continuously wear away particles from the surface. It is possible to generate $150,000,000$ particles 1.0 micron in size by wearing away a thickness of 1 micron ( 0.000040 inch) from an area the size of a postage stamp. ${ }^{2}$ Also, cracks in floor coverings catch dirt which is usually not removed during cleaning operations. These dirt particles are continually stiried up as personnel move about in the rooms. Monolithic types of coverings of vinyl or similar hard-surface, abrasiveresistant materials with sealed joints will reduce problems with particulate matter whether or not our standards activity is seeking cleanroom-type control. On the other hand, cracks around abrasive-resistant square floor tiles may be difflcult to seal effectively and economically. Light-colored floors give good reflectivity characteristics.

Sandia Corporation has developed a cleanroom with a steel grating floor. ${ }^{3}$ Dirt and particulate matter fall through the grating and are trapped by a filter below the floor level. This construction offers the least personnel control nuisances that we know of and is compatible with the best particulate matter counts that have been made. The particulate matter is held to the filter by fan suction pressure. The accumulation of fallout is cleaned by removing the grates and periodically using an absolute vacuum sweeper with special after filters. Equipment would be set on concrete pedestals that could project through the gratings to the required height.

Superior numbers refer to similarly-numbered references at the end of this paper. 


\section{Entrances and Windows.}

Airlocks - - Airlocks should be large enough (about $5 \times 10$ feet) to allow three to five people to enter the measurement room at one time. Warning horns can be set up to blow when both doors to critical dust count and temperature-controlled areas are open. Interlock systems have also been used, but failure of such systems may trap personnel in airlocks or in rooms. Static air pressure within the airlock should be positive at all times with respect to halls and outside spaces, but less than respective room pressure. Walk-through type shoe sole cleaners may be installed in airlocks to reduce the particles carried in by personnel.

Windows - - No outside windows should be allowed in the measurement areas. Moderatesize thermopane windows in inside walls will. allow visitor observation of laboratory practices and reduce the traffic into the measurement areas.

Pass Boxes - - If pass boxes or windows are used in a standards laboratory to limit traffic, the counter tops should be constructed of stainless steel, formica, or similar abraoive-resistant material. Even though pass boxes are not common in standards laboratories, they may be practical in some applications. Warning horns, as used in airlocks, are recommended.

\section{Utilities}

Lighting -- Four factors are interrelated in the task of seeing--size, brightness, contrast, and time. Variations in one factor may affect the others; thus, increasing the brightness enables the eye to see objects both smaller in size and lower in contrast and to recognize objects more quickly and with less confusion.

The illumination level recommended most often for general work and office areas is 1.00 foot-candles at 30 inches working height--with finer work requiring up to 200 foot-candles. ${ }^{4}$ However, 70-80 foot-candles is satisfactory in most standards activities at Sandia Corporation. Many times optical equipment or galvanometers are operated with half or more of the lamp fixtures turned off to allow use of the lighting in the equipment and to reduce the heat gain from the lights. This heat gain is particularly undesirable when calibrating the longer gage blocks. To permit individual equipment lighting control, individual pull chains are used in our dimensional laboratory.

Wall color and smoothness will affect the lighting levels and must be considered. Bright surfaces reflect more light than dark, rough surfaces; a light-colored, polished floor, for example, will reflect light back to the ceiling and reduce the contrast between the ceiling surface and the light fixture.

Another factor is glare, both direct and indirect. Direct glare is emitted from a fixture at 45 to 90 degrees; reflected or indirect glare is emitted at 0 - to 45 -degree angles. Prismatic glass luminaires reduce direct glare without losing efficiency. Reflected glare can be reduced by arrangement of fixtures and furniture.

Because electronic work areas, especially radio frequency and microwave areas, must be free of radio frequency interference, the most common lighting is by incandescent bulbs which have lower interference factors than fluorescent tubes. Where fluorescent fixtures are installed, specially-coated, low-brightness glass lenses may be used to conduct off the radio frequency radiation. In screened rouns radiation from fluorescent fixtures may be reduced by placing fixtures outside the screens. Also, a filter in the power line will eliminate conducted radio frequency interference.

Our discussion of lighting would not be complete without something about the economics of lighting. Both building and air conditioning load maintenance costs can be reduced by not over illuminating. Obviously the more heat from lighting, the higher the air conditioning cost. Also, group replacement of lamps, whether burned out or not; can save labor costs and work disruptions.

Vacuum systems -- Installed (that is permanent) vacuum systems are desirable in receiving, precleaning, and cleaning operations where high volumes of particulate matter are involved. Such matter can be exhausted into large volume tanks outside the laboratory or in the basement. Portable, absolute-type vacuum cleaners with filtered exhausts are satisfactory for measurement areas. Ordinary household and commercial vacuum cleaners exhaust fine dust back into the room. In a cleanroom-type operation fewer absolute cleaners will be required. 
Utility outlets -- Outlets for water, gases, high vacuum, and air should be planned for each measurement activity since the location of a utility may limit the location of an operation. All mechanical piping should be brought into the measurement areas through the walls; floor piping, as I mentioned, can transmit vibration to measuring equipment. Bottles for the various gases required can be connected outside the building.

Absolute filters are available for compressed air supplies where dir is uscd in a measuring operation or any other operation within a measurement area. The average commercial. air filter will not provide the degree of filtering available in an absolute filter.

Electric power, voltage regulation and electrical outlets -- A standards laburatory should have separate input power transformers and power lines to avoid intralaboratory interactions and to reduce the chance of receiving switching and loading transients from other plant operations. The grounding systems should provide equal ground potentials throughout the laboratory.

Voltage regulation in electrical measurement activities is usually satisfactory at \pm 5 percent; special regulators are required where special instrument requirements are involved. Dimensional laboratories, surprisingly enough, may require \pm 1 percent or better regulation. Vacuum tube amplifiers used.as "null" indicators are particularly sensitive to line voltage variations. Small portable regulators at 250 watts or hetter may be adequate for such work.

The number, rating, and location of electrical outlets will be dictated largely by equipment used. Special requirements, present or future, should be provided for in the plans.

Intercommunication systems and telephones - - Whether or not telephones or intercommunications systems will be installed in the measurement areas is frequently a matter of plant policy. Intercommunication systems introduce an undesirable noise problem unless a limited number of calls only are permitted or received. Ringing phones in the work areas are certainly distracting. If incoming calls are received by a secretary or clerk and a light or buzzer and light system is used to identify the person wanted, the confuston and noise level problems can be reduced.

\section{Environments}

The basic environmental requirements to be met for precision measurements in a standards laboratory are covered by other papers in this series of presentations. However, since misunderstandings do exist about some requirements, tolerances, rates of change and where and at how many places conditions will be measured, I will make a few comments on these particulars.

Temperature -- If a particular air conditioning consultant cannot cope with conditions such as $\pm 2^{\circ} \mathrm{F}$ variation from nominal and a rate of change not greater than 3 degrees per hour, special industrial controls are available with adjustable proportional total band sprcads, rateof-change factors, and reset cuntrols required to meet special rate-nf-change requirements. (For controlled temperature rooms we also should spccify static air pressures which are positive with respect to pressures in airlocks and halls.)

The temperature of recirculated air can be better controlled when heating is by forced hot water circulation rather than by steam-type blast coils. In air conditioning systems return air should be preheated to a fixed temperature upstream of the cooling coil to minimize temperature fluctuation. Fluctuations also are less with chilled water cooling than with direct expansion cooling. A secondary circulating pump can insure constant flow through cooling coils in the chilled water system. However, areas with temperature requirements as tight as $\pm 1 / 10^{\circ}$ or $1 / 4^{\circ} \mathrm{F}$ should have separate air conditioning systems since response rates from central system take-offs are usually too slow.

Relative humidity -- Commercial relative humidity controls are gond to about \pm 5 percent. Tolerance requirements down to \pm 2 percent can be met consistently only under laboratory conditions. Specifications for \pm 1 percent and \pm 2 percent of nominal relative humidity will require specially-designed controls and actuators.

Humidity ranges from 35 percent to 45 percent are preferred in $68^{\circ} \mathrm{F}$ areas. We might also note that humidity controls are simpler and more reliable and respond more satisfactorily with air wash-sprayed coil systems than with steam systems.

Cooling towers used for the refrigeration units in humidity control systems should stand on 
concrete pads outside the laboratory buildings with gravity drains to storage tanks inside equipment rooms. This reduces the danger of freezing in winter during power failure. We should avoid using roofs above standard laboratories for cooling towers; vibrations from such towers can be transmitted into laboratory areas.

Vibration and shock limitations -- Certain vibrations are very undesirable in a standards laboratory, but a requirement that your laboratory be free from excessive vibrations is confusing. What is excessive? This is a problem of continued research and study. An article in the February 1961 issue of ISA recommended vibration limitations of $0.001 \mathrm{~g}$ maximum acceleration with no frequency limitation. At 2 cycles per second, $0.001 \mathrm{~g}$ equals 4892 microinches displacement; at 60 cycles per second, $0.001 \mathrm{~g}$ equals 12 microinches displacement $\left(g=0.0511 \mathrm{df}^{2}\right.$ with $d$ equal to displacement-inches peak to peak and $f$ equal to frequency in cyles per second). Thus vibration requirements should have frequency limitations as well as acceleration or displacement limitations.

A vibration suiv vey shouid uncover most disturbing shock pulses stemming from natural or man-made causes. The steps taken to isolate a slab and building against ground vibrations will also dampen shock pulses. If unusual conditions exist, vibration and shock experts can be helpful.

Dust and corrosive vapor control -- Modern absolute filters (99. 97\% efficiency) and laminar flow air will supply low dust count air. The lowest known counts are found in connection with grated floors and absolute filter banks at air velocities up to 120 feet per minute. This type of construction may not be applicable to your working situation, but the application of cleanroom principles, even in a limited fashion, will reduce dust problems.

Personnel are the biggest single contributors to dust problems. In most cleanrooms as the number of people moving about increases, the dust count goes up. Various measures, such as special clothing, can reduce the chance of personnel carrying particulate matter into cleanrooms. Where a stringent dust control requirement exists, we should determine whether the acceptance counts should be made with personnel in the room. Both dust and corrosive vapors from within plant operations can be excluded from standards areas to a certain extent by operating such areas at positive pressure relative to corridors, halls, and surrounding work. Air conditioning--sprayedcoil systems using air washers--will remove most of the dust and vapors from incoming air.

Electrical and radio frequency noise protection - - Shielded rooms are available in package forms and we recommend this approach to shielding problems. Manufacturers' claims for shielded room performance should be investigated very carefully. A performancecontingency clause in the purchase contract should not be neglected.

Acoustic noise protection -- Acoustic materials are quite often a source of particulate matter that may affect your dust count problems. Investigate the shedding characteristics of any acoustic material you specify.

SOME METHODS OF COMBATING UNFAVORABLE ENVIRONMENTS WITHIN AN EXISTING STRUCTURE

Economy-minded management cannot always see the wisrinm of building a new laboratory structure when so many thousands of dollars are already tied-up in an existing structure. Yet to convert an existing structure to a standards laboratory with the proper environments costs one and one-half to three times the cost of a new laboratory, according to current estimates. And then we do not have all of the conditions that could be obtained in a new, properly planned and adequately designed laboratory. Such arguments may not shake management's position, however. Therefore, we shall take a practical approach to improving conditions.

Obviously we can purchase prefabricated laboratories to be placed within large rooms. Or we can remove outside wall windows in work areas, provide double walls (converted to return air spaces), and replace ceiling tile with perforated metal where space exists above the ceiling for a supply air plenum. We can remove dirt catching ledges throughout the rooms, replace inadequate furniture with abrasive-free materials, and install observation windows to cut traffic conditions. We can revamp the lighting and air conditioning systems (with due patience and headaches) and replace floor coverings with nonshedding materials and build airlocks and install shoe cleaners. But what do we do about vibrations? 
When floor slabs are not isolated and are criss-crossed with conduit and piping, we have to isolate individual pieces of equipment on springs and concrete blocks. The concrete blocks should be as massive as possible within space and furniture limitations. The suppliers of spring isolators can help determine what springs to use. Soft springs are considered better isolators, yet equipment supported on soft springs may move every time someone touches it. Therefore in the Sandia Corporation primary length and mass laboratories we use stiff springs to reduce the disturbing vibrations. Sprincs have provided workable isolation from floor vibrations of up to $0.0007 \mathrm{~g}$ at $14 \mathrm{cps}$ (70 microinches) and $0.0011 \mathrm{~g}$ at $30 \mathrm{cps}(24$ microinches).

Other solutions include mounting reflecting galvanometers on special platforms and tables. These platforms may be suspended on springs and dashpots of your own design or obtained commercially. While not ideal, such adaptations provide working possibilities in otherwise intolerable situations. It should be understood, however, that more patience and time is required to use equipment when it must be isolated in such a manner.

\section{CONCLIISION}

Obtaining and maintaining a laboratory structure that provides satisfactory environments and working conditions for calibration measurements is a dynamic problem whether you have a small operation or a part of a complex of standards lahoratories. And we should remember that criteria for building of a laboratory at one location may or may not be satisfactory fur another laboratory. But we are learning. As more measurements of conditions before and after building laboratories are gathered and analyzed, it may be possible to develop a package of requirements for laboratory classifications. To develop these requirements, however, we need detailed information and measurements and analyses and not rationalization about what might work.

Finally, although I have not discussed packaged laboratory rooms, they are now on the market and they should not be overlooked. They provide many of the characteristics we have discussed. And perhaps these packaged rooms indicate that development of uniform laboratory structures for standards measurement and calibration activities is well underway.

\section{REFERENCES}

(1) Standards and Guidelines for the Design and Operation of Environmentally Controlled Facilities, US Air Force TO 00-25-203.

(2) Vance, Donald H., "Steel-Spring Type Vibration Mountings for Machine Tools, " presented at the Nineteenth Annual Meeting of American Society of Tool Engineers, March 15-17, 1951.

(3) Whitfield, W. J., "A New Approach to Cleanroom Design, "Sandia Corporation Report SC-4673(RR).

(4) Delude, Richard, "Lighting for R\&D Areas," Research/Development., May 1963.

\section{BIBLIOGRAPHY}

(1) Ilorton, Wallace. I.. "USAF's New Calibration Center, "ISA Journal, January 1961.

(2) ISA Measurement Standards Division Task Force, "Recommended Environments for Standards Laboratories, " ISA Journal, February 1961, Vol. 8, No. 2.

(3) "Laboratory Facilities and Layout," Standards Laboratory Information Manual, Naval Inspector of Ordnance, Pomona, Calif.

(4) Marsh, R. C., "Adaptability of Laminar Air Flow for Contamination Control, " Contamination Control Journal, May 1963.

(5) McQuade, Walter, "The Telephone Company Dials the Moon, "Architectural Forum, October 1962.

(0) Medvcdoff, André" S. "Environments and the Standards Laboratory, "Activities Report of the Environmental Standards Committce...American Ordnance Association, January 1961.

(7) Repair, Calibration and Certification of Precision Measurement Equipment, US Air Force Technical Manual TO 33-1-14, October 1962.

(8) Vance, Donald H. , "The Use of Vibration and Shock Control in Reducing Noise Levels," Noise Control, March 1956.

(9) White, Charles E., "Instrumentation Precision as Affected by Vibrational Environment, " Instruments and Control Systems, June 1960.

(10) Whitfield, "State-of-the-Art (Contamination Control) and Laminar Air Flow Concept," Sandia Corporation Reprint SCR-652. 